\title{
LARCs after unsafe abortion in Libreville (Gabon): Women accept quickly but the time interval for the insertion is longer than that of injectable contraceptives
}

\author{
Sosthène Mayi-Tsonga ${ }^{{ }^{*}}$, Jacques Bang Ntamack ${ }^{1}$, Boniface Sima-Ole ${ }^{1}$, Pamphile Assoumou Obiang ${ }^{2}$, \\ Ulysse Minkobame $^{2}$, Doris Ngouafo ${ }^{2}$ \\ ${ }^{1}$ Faculty of Health Sciences of Libreville, Gabon, Africa \\ ${ }^{2}$ Department of Obstetrics and Gynecology of University Hospital of Libreville, Gabon, Africa \\ Email: smayi3@yahoo.fr \\ Received 18 November 2013; revised 15 December 2013; accepted 23 December 2013 \\ Copyright (C) 2014 Sosthène Mayi-Tsonga et al. This is an open access article distributed under the Creative Commons Attribution \\ License, which permits unrestricted use, distribution, and reproduction in any medium, provided the original work is properly cited. \\ In accordance of the Creative Commons Attribution License all Copyrights @ 2014 are reserved for SCIRP and the owner of the \\ intellectual property Sosthène Mayi-Tsonga et al. All Copyright (C) 2014 are guarded by law and by SCIRP as a guardian.
}

\section{ABSTRACT}

Objectives: To determine the percentage of women who accepted a LARC after abortion, specify the interval time for the insertion of the LARC and compare such interval time with that of injectable and oral contraceptives. Patients and Methods: This is a prospective, descriptive and comparative study conducted in Libreville (Gabon), from February 1, 2013 to August 31, 2013. After receiving post-abortion care (PAC), all patients with stable general states were counseled about three types of contraceptive methods: combined oral contraceptive pills, LARCs (Jadelle ${ }^{\circledR}$ implants, Copper IUDs) and injectable Medroxyprogesterone Acetate (DMPA). Results: 231 women received PAC and among them 215 (93\%) wanted to use one of the three proposed contraceptive methods. At the end of the study, only 193 women (89.7\%) used contraception and 22 others (10.3\%) abandoned their intentions. LARCs were used by $31 \mathbf{( 1 6 . 0 \% )}$ women. The average period for the insertion of LARCs was $15.4 \pm 15.5$ days with extremes of 1 to 53 days. This period for the insertion of LARCS was significantly longer than that of other methods $(p<0.001)$. LARCs were inserted more often after the $2^{\text {nd }}$ day than immediately (same day) with a highly significant difference $(p<0.0001)$. Conclusion: LARCs could constitute an appropriate approach to reducing unintended pregnancies in Gabon. However, in order to increase their rates of use, it is necessary to improve women awareness.

${ }^{*}$ Corresponding author.

\section{KEYWORDS}

Unsafe Abortion; Contraception; LARC; Period for the Insertion of LARCs; Gabon

\section{INTRODUCTION}

Long-acting reversible contraceptive (LARC) methods are more effective than oral contraceptive pills and injectable contraceptives for preventing unintended pregnancies [1]. The immediate post-abortion period, just after PAC, is a right moment to suggest the insertion of a LARC, particularly after clandestine induced abortion. That period has many advantages, among which is the certainty that the woman is no longer pregnant and is located in a health facility. This leads to the opportunity to provide her with information about contraception. The insertion of subdermal implants (Jadelle implants) or IUDs is easy, fast and safe for the woman. They provide an effective and long-term protection from unintended pregnancies. We conducted a prospective study in order to increase the use of LARCs in post-abortion period, immediately after post-abortion care (PAC). The objectives were to determine the percentage of women who accept LARCs on the same day of PAC, specify the time interval for the insertion of LARCs and compare it with that of injectable and oral contraceptives.

\section{PATIENTS AND METHODS}

This is a prospective, descriptive and comparative study conducted at Libreville's university hospital (CHUL), the main maternity hospital in Gabon. The study took place over a seven-month period, from February 1, 2013 to Au- 
gust 31, 2013. Patients were coming from the general population of Libreville, the country's capital city. Gabon is a country in Central Africa with a population of 1.5 million inhabitants of which nearly $60 \%$ live in Libreville. The maternity department of CHUL is the largest nationwide with almost 8000 deliveries per year and about 8\% of abortion cases treated annually.

I order to improve the availability of modern methods of contraception in our department, we developed standard investigative procedures in collaboration with Gabonese Society of Gynecology-Obstetrics and Reproduction (SGGOR). Such procedures were approved by the National Committee of Ethics and Research in Gabon (NCERG). Therefore, after post-abortion care (PAC), all patients with stable general states, were counseled about three types of modern contraceptives: combined oral contraceptive pills, LARCs (Jadelle ${ }^{\circledR}$ implants and copper IUDs) and three months injectable Medroxyprogesterone Acetate (DMPA). In order to push for the use of LARCs and injectable contraceptives, these two last contraceptive methods were provided free of charge. Women who chose oral contraceptive pills had to buy it on their own when leaving the hospital. We excluded women with such poor general states after PAC that they could not answer questions.

Counseling was provided immediately after PAC, in a confidential manner, and as for teenagers, approval from a member of the family or accompanying adult was required. Detailed information was provided about the use of each method, their advantages and side effects. On recommendation of the NCERG, we exerted no pressure on patients. Therefore, among those who preferred a LARC or an injectable, the insertion thereof was either immediate, if the patient wanted so, or deferred when the woman wanted an additional reflection period. In such case, we let women go back home after they promised they will come back to hospital to be inserted the LARC or IUD. We regularly contacted them by telephone, every second day, so as to get their final consent.

All included patients left the hospital in the first 24 hours after receiving PAC. Data on socio-the demographic characteristics (age, marital status, employment, level of education, parity, previous unsafe abortion and gestational age), the contraceptive option just after PAC, the contraceptive method received and the time interval for the insertion of each method were collected in individual files. Data were analyzed using SPSS 18 software. The dependent variable was the time interval for the insertion of LARCs. The independent variables were age $(<18$ years $/ \geq 18$ years), marital status (single/others), employment (students/other), level of education (primary or less/secondary or higher), parity $(0 / \geq 1)$, previous unsafe abortion $(0 / \geq 1)$ and gestational age $(\leq 10 />10 \mathrm{WA})$. Univariate analysis was conducted to describe the epidemi- ological profile of women who accepted to receive contraceptive methods. Multivariate analysis allowed researching for associations between dependent and independent variables. Chi-square test, t-test or Fisher's exact test were used to study associations between variables, with a p-value $\leq 5 \%$. To estimate the dispersion of interval time to initiate each method, we calculated the interquartile range (IQR) from plain-text box plot with the formula of IQR = Q3 - Q1 where Q3 is the upper quartile and Q1 the lower quartile.

\section{RESULTS}

There were 231 cases of unsafe abortion handled in the department. Among those women, 215 (93\%) after being counseling, accepted to receive one of three proposed contraceptive methods. None of them (100\%) knew about LARCs.

The mean age was $24.5 \pm 5.7$ years with extremes of 14 and 40 years. The mean parity was $1.8 \pm 1.7$ with extremes of 0 and 9 . The mean gestational age was $12.0 \pm$ 4.6 weeks of amenorrhea (WA) with extremes of 7 and 28 WA. The women were single (62.3\% or 134 cases), living in non-marital cohabitations (31.2\% or 67 cases) or married (6.5\% or 14 cases). They were student $(43.7 \%$ or 94 cases), unemployed (30.2\% or 65 cases) or employed (26.1\% or 56 cases). The level of education was secondary or higher for 206 women (95.8\%) and primary or less for 9 cases (4.2\%).

The majority of women wanted to use contraceptive pills (55.4\% or 119 cases). The others wanted to use injectable DMPA (22.3\% or 48 cases) and LARCs (22.3\% or 48 cases).

At the end of the study, 22 (10.2\%) patients did not honor their intention to use contraception. Finally, only 193 women $(89.7 \%$ or $193 / 215)$ received a contraceptive method. LARCs were used by 31 (16.1\% of 193 cases) women as shown in Table 1.

The Jadelle implant was the only type of LARC used by the women who chose such contraceptive method.

The mean time for inserting the 3 methods was 5.3 days and ranged from 53 days to 1 day with an IQR of 6 days. The IQR of the LARC was 17 days compared to 6 days for Injectable/Pills (Tables 2(a) and (b)).

Table 1. Contraceptive methods used $(n=193)$.

\begin{tabular}{ccc}
\hline & $\mathbf{N}$ & $\%$ \\
\hline Oral Combined Pill & $\mathbf{1 1 6}$ & $\mathbf{6 0 . 1}$ \\
DMPA Injectable & $\mathbf{4 6}$ & $\mathbf{2 3 . 8}$ \\
LARC & $\mathbf{3 1}$ & $\mathbf{1 6 . 1}$ \\
Implant & 31 & 16.1 \\
IUD & 0 & 0 \\
Total & $\mathbf{1 9 3}$ & $\mathbf{1 0 0}$ \\
\hline
\end{tabular}


Table 2. (a) Mean time for inserting the 3 methods $(\mathrm{n}=193)$; (b) IQR for inserting the 3 methods $(n=193)$.

(a)

\begin{tabular}{cccccc}
\hline $\begin{array}{c}\text { Contraceptive } \\
\text { Method Used }\end{array}$ & Mean & Min. & Max. & Asy. & $\begin{array}{c}\text { St. Err. } \\
\text { of mean }\end{array}$ \\
\hline Pills (n = 116) & 2.1 & 1 & 7 & 1.5 & 0.2 \\
Injectable (n= 46) & 6.6 & 1 & 36 & 2.1 & 1.2 \\
$\begin{array}{c}\text { Injectable/Pill } \\
(\mathbf{n}=\mathbf{1 6 2})\end{array}$ & 3.4 & 1 & 36 & 3.6 & 0.4 \\
LARC (n= 31) & 15.4 & 1 & 53 & 1.3 & 2.7 \\
Total (n= 193) & 5.3 & 1 & 53 & 3.3 & 0.6 \\
\hline
\end{tabular}

Min. = minimum; Max. = maximum; Asy. $=$ asymmetry; St. err. $=$ Standard Error.

(b)

\begin{tabular}{ccccc}
\hline $\begin{array}{c}\text { Contraceptive } \\
\text { Method Used }\end{array}$ & Q1 & Q2 & Q3 & IQR \\
\hline Pills (n = 116) & 1 & 1 & 1 & 0 \\
Injectable (n = 46) & 1 & 3 & 7.2 & 6.2 \\
Injectable/Pill (n = 162) & 1 & 1 & 7 & 6 \\
LARC (n= 31) & 6 & 8 & 23 & 17 \\
Total (n= 193) & 1 & 1 & 7 & 6
\end{tabular}

Q: Quartile; IQR = Inter Quartile Range.

The time interval for inserting LARCs was significantly longer than that of injectable contraceptives/contraceptive pills $(\mathrm{p}<0.001)$ as shown in Table 3 .

When comparing the interval time for the insertion of LARCs and that of injectable contraceptives/contraceptive pills, we noted that LARCs were inserted more often beyond the $2^{\text {nd }}$ day than immediately (same day) with a highly significant difference $(p<0.0001)$ as shown on Table 4.

Multivariate analysis found no association between the time interval for the insertion of LARCs and independent variables, as indicated in Table 5 .

\section{DISCUSSION}

In order to reduce unwanted pregnancies and unsafe abortion in countries where laws prohibit voluntary termination of pregnancy, it is imperative to increase the availability and access to long-acting contraceptive methods such as LARCs. Their advantages are well known in terms of effectiveness and tolerance. They are constraint-free since they are administered in single dose and last for long.

The percentage of women who accepted one of the three methods of contraception immediately after being counseled is very high, as well as that of the women who actually received a contraception. Such high rates of ac-
Table 3. Mean time (days) for inserting LARC $(n=31)$ and Injectable/Pills $(\mathrm{n}=162)$.

\begin{tabular}{|c|c|c|c|c|c|c|}
\hline \multirow{2}{*}{$\begin{array}{l}\text { Mean } \\
\text { time }\end{array}$} & \multirow{2}{*}{$\mathbf{t}$} & \multirow{2}{*}{ ddl } & \multirow{2}{*}{ Sig. (bil.) } & \multirow{2}{*}{ Mean } & \multicolumn{2}{|c|}{ IC $95 \%$} \\
\hline & & & & & Inf. & Sup. \\
\hline LARC $(n=31)$ & 5.5 & 30 & .000 & 15.4 & 9.7 & 21.1 \\
\hline $\begin{array}{c}\text { Injectable/Pill } \\
(\mathrm{n}=162)\end{array}$ & 8.2 & 161 & .000 & 3.4 & 2.6 & 4.2 \\
\hline
\end{tabular}

Table 4. Insertion the same day (LARC versus Injectable/Pill).

\begin{tabular}{cccc}
\hline & LARC N(\%) & Injectable/Pill N(\%) & $\mathbf{p}^{\mathbf{a}}$ \\
\hline Time (days) & & & \\
$\leq 1(\mathrm{n}=112)$ & $2(1.7)$ & $110(98.2)$ & $<\mathbf{0 . 0 0 0 1}$ \\
$\geq 2(\mathrm{n}=81)$ & $29(35.8)$ & $52(64.1)$ & \\
& & $\mathbf{1 6 2 ( 8 3 . 9 )}$ & \\
Total (n= 193) & $\mathbf{3 1 ( 1 6 . 1 )}$ &
\end{tabular}

Table 5. Determinants of the immediate insertion of the LARC $(\mathrm{n}=31)$.

\begin{tabular}{|c|c|c|c|c|}
\hline \multirow[t]{2}{*}{$N=31$} & \multicolumn{2}{|c|}{$\begin{array}{c}\text { Time Insertion of LARC } \\
\text { (days) }\end{array}$} & \multirow{2}{*}{$\begin{array}{l}\text { Total } \\
\text { N (\%) }\end{array}$} & \multirow{2}{*}{$\mathbf{p}^{\mathrm{b}}$} \\
\hline & $\begin{array}{l}\text { Same day } \\
\mathrm{N}(\%)\end{array}$ & $\begin{array}{c}\geq 2 \\
\mathrm{~N}(\%)\end{array}$ & & \\
\hline \multicolumn{5}{|l|}{ Age (Years) } \\
\hline$<18$ & $1(20)$ & $4(80)$ & $5(16)$ & \\
\hline$\geq 18$ & $1(3.8)$ & $25(96.2)$ & $26(84)$ & 0.301 \\
\hline \multicolumn{5}{|l|}{ Employment } \\
\hline $\begin{array}{c}\text { Students } \\
\text { Others }\end{array}$ & $\begin{array}{l}1(50) \\
1(3.4)\end{array}$ & $\begin{array}{c}1(50) \\
28(96.6)\end{array}$ & $\begin{array}{c}2(6.5) \\
29(93.5)\end{array}$ & 0.126 \\
\hline \multicolumn{5}{|l|}{ Marital Status } \\
\hline $\begin{array}{l}\text { Single } \\
\text { Others }\end{array}$ & $\begin{array}{c}2(10.3) \\
0(0)\end{array}$ & $\begin{array}{l}13(86.7) \\
16(100)\end{array}$ & $\begin{array}{l}15(48) \\
16(52)\end{array}$ & 0.225 \\
\hline \multicolumn{5}{|l|}{$\begin{array}{l}\text { Level of } \\
\text { Education }\end{array}$} \\
\hline Primary or less & $0(0)$ & $2(100)$ & $2(6.5)$ & 0.873 \\
\hline over & $2(6.9)$ & 27(93.1) & 29(93.5) & \\
\hline \multicolumn{5}{|l|}{ Parity (n) } \\
\hline 0 & $0(0)$ & $6(100)$ & $6(19)$ & 0.645 \\
\hline$\geq 1$ & $2(8.0)$ & $23(92.0)$ & $25(81)$ & \\
\hline \multicolumn{5}{|l|}{$\begin{array}{c}\text { Previous } \\
\text { Unsafe } \\
\text { Abortion (n) }\end{array}$} \\
\hline 0 & $1(6.3)$ & $15(93.7)$ & $16(52)$ & 0.741 \\
\hline$\geq 1$ & $1(6.7)$ & 14(93.3) & $15(48)$ & \\
\hline \multicolumn{5}{|l|}{$\begin{array}{l}\text { Gestational Age } \\
\text { (WA) }\end{array}$} \\
\hline $\begin{array}{l}\leq 10 \\
>10\end{array}$ & $\begin{array}{l}1(12.5) \\
1(4.3)\end{array}$ & $\begin{array}{c}7(87.5) \\
22(95.7)\end{array}$ & $\begin{array}{l}8(26) \\
23(74)\end{array}$ & 0.455 \\
\hline
\end{tabular}

${ }^{\mathrm{b}}$ Fisher’s exact test. 
ceptability show that the need for effective contraception remain major in women admitted in our department for clandestine abortion complications. However, if women very quickly and massively accept a modern method of contraception, we are surprised by the time interval for the insertion which seems too long especially for LARCs and injectable contraceptives. We thought that providing such contraceptives for free could quickly and more often encourage women to use them [2,3], especially as their insertion is quick (case of injectable contraceptives) or requires a light local anesthesia (case of sub dermal implants).

It is essential that these long-acting methods of contraception are inserted quickly after PAC since this is a favorable period. Indeed, a great percentage of women aborting clandestinely in low-income countries and especially in Africa do not go to health-care centers. Such women prefer using self-medication or consulting nonmedical providers. This can constitute an additional risk of serious complications. This moment of meeting between patients and medical providers at hospital should be used to offer and quickly insert such contraceptive methods. Moreover, health-care providers in our department are often reluctant to quickly provide women consulting for unsafe abortion complications [4] with PAC, even though improvements were observed recently [5].

Though inserting LARCs on the same day remains difficult [6] and depends on the quality of counseling [69]. Our mean period for the insertion of LARCs is less than that of Tocce [10] who found a mean period of $18 \pm$ 13 days for the insertion of etonogetrel implants in postpartum teenagers. While comparing the interval time for the insertion of etonogetrel implants and IUDs, Tocce's study [10] also found a longer period for the insertion of implants.

The factors influencing post-abortion and post-partum contraceptive option are well known. In Africa, youth (aged 25 - 29) and the high level of education (secondary and higher) are the main factors determining the option for LARCs [11-14]. The more women are educated, the less they have taboos regarding the use of modern methods of contraception and especially LARCs [11-14].

However, the factors determining the immediate insertion of LARCs in women after abortion remain known. Indeed, there are few studies on post-abortive use of LARCs. It is likely that the quality of counseling and that of the counseling provider could be very determinant for to accept the insertion of LARCs on the same day, postabortion as well as post-partum [2,3,6-9]. This is what could explain the fact that we have not found a statistical association between the dependent variable and independent variables. A larger-scale study is required to determine the factors influencing the immediate insertion of LARCs post-abortion.

\section{CONCLUSION}

This study found a low level rate of use of LARCs post abortion. The mean period for the insertion of LARCs was longer than that of injectable contraceptive and oral contraceptive. In order to increase the use of LARCs and expect more consent for their insertions the same day as that of the uterine evacuation, we need to better inform women on the benefits of long acting contraceptive method.

\section{REFERENCES}

[1] ACOG Practice No. 121 (2011) Long-acting reversible contraception: Implants and intrauterine devices. American College of Obstetricians and Gynecologists. Obstetrics \& Gynecology, 118, 184-196. http://dx.doi.org/10.1097/AOG.0b013e318227f05e

[2] Peipert, J.F., Madden, T., Allsworth, J.E. and Secura, G.M. (2012) Preventing unintended pregnancies by providing no-cost contraception. Obstetrics \& Gynecology, 120, 1291-1297.

[3] Eisenberg, D., McNicholas, C. and Peipert, J.F. (2013) Cost as a barrier to long-acting reversible contraceptive (LARC) use in adolescents. Journal of Adolescent Health, 52, S59-S63. http://dx.doi.org/10.1016/j.jadohealth.2013.01.012

[4] Mayi-Tsonga, S., Litovchenko, O., Ndombi, I., De Souza, M.H. and Faundes, A. (2009) Delay in provision of adequate care to women who died from abortions related complications in the principal maternity of Libreville in Gabon. Reproductive Health Matters, 17, 65-70. http://dx.doi.org/10.1016/S0968-8080(09)34465-1

[5] Mayi-Tsonga, S., Assoumou, P., Sima Olé, B., Bang, J., Meye, J.F. and Faundes, A. (2012) The contribution of research results to improvement abortion care in Libreville. Reproductive Health Matters, 20, 16-21. http://dx.doi.org/10.1016/S0968-8080(12)40670-X

[6] Biggs, M.A., Arons, A., Turner, R. and Brindis, C.D. (2013) Same-day LARC insertion attitudes and practices. Contraception, 88, 629-635. http://dx.doi.org/10.1016/j.contraception.2013.05.012

[7] Morse, J., Freedman, L., Speidel, J.J., Thompson, K.M., Stratton, L. and Harper, C.C. (2012) Postabortion contraception: Qualitative interviews on counseling and provision of long-acting reversible contraceptive methods. Perspectives on Sexual and Reproductive Health, 44, 100106. http://dx.doi.org/10.1363/4410012

[8] Rose, S.B., Lawton, B.A. and Brown, S.A. (2010) Uptake and adherence to long-acting reversible contraception post-abortion. Contraception, 82, 345-353. http://dx.doi.org/10.1016/j.contraception.2010.04.021

[9] Lewis, C., Darney, P. and Thiel de Bocanegra, H. (2013) Intrauterine contraception: Impact of provider training on participant knowledge and provision. Contraception, 88, 226-231. http://dx.doi.org/10.1016/j.contraception.2013.06.004

[10] Tocce, K., Sheeder, J., Python, J. and Teal, S.B. (2012) 
Long acting reversible contraception in postpartum adolescents: Early initiation of etonogestrel implant is superior to IUDs in the outpatient setting. Journal of Pediatric and Adolescent Gynecology, 25, 59-63.

http://dx.doi.org/10.1016/j.jpag.2011.09.003

[11] Prata, N., Bell, S., Holston, M., Gerdts, C. and Melkamu, Y. (2011) Factors associated with choice of post-abortion contraception in Addis Ababa, Ethiopia. African Journal of Reproductive Health, 15, 51-57.

[12] Family Health International (2008) Africa: Fill the unmet need in family planning. The arguments in favor of permanent and long acting methods (PLAM) New York. Triangle Park.

[13] Demographic Survey of Health of Gabon (2012) Libreville. MSP/DGS. 2nd Edition.

[14] Mahomed, K., Healy, J. and Tandom, S. (1997) Family planning counselling a priority for post abortion care. Central African Journal of Medicine, 43, 205-207. 